\title{
Caracterização ambiental e agrícola da unidade produtiva dos agricultores familiares da comunidade Moura
}

\author{
Environmental characterization and agricultural production unit of family farmers in the community of Moura. \\ Adailza Guilherme da Silva', Alian Cassio Pereira Cavalcante ${ }^{2}$, Maria Jose Ramos da Silva \\ 'Universidade Federal da Paraíba UFPB. Graduanda de Bacharelado em Agroecologia - PB - Brasil \\ ${ }^{2}$ Universidade Federal da Paraíba UFPB. Licenciando em Ciências Agrarias - PB - Brasil \\ ${ }^{3}$ Pós-graduanda em Ciências Agrárias e (Agroecologia), Universidade Federal da Paraíba.- PB - Brasil
}

\begin{abstract}
Resumo
O ambiente agrícola é alvo de especulação e estudo com intuito de aperfeiçoar o desenho dos agroecossistemas sem interferir de forma agressiva, para atingir o bem-estar social da comunidade e a preservação do meio ambiente só é possível mediante manejos sustentáveis dos sistemas agrícolas. $\mathrm{O}$ trabalho objetivou-se identificar o perfil socioeconômico dos agricultores e os seus respectivos cuidados com as questões ambientais nas unidades produtivas da comunidade Moura. Para a realização do trabalho foram feitas visitas a comunidade durante o mês de Agosto de 2013, e para o levantamento foram realizadas entrevistas com auxilio de questionários semiestruturados constituído de questões de caráter social, ambiental e agrícola. Os agricultores da comunidade Moura, $44 \%$ são do gênero masculino e $54 \%$ feminino, $67 \%$ tem de 1 a 2 salários mínimos e 33\% menos de um salário mínimo, os problemas ambientais existente na comunidade causado pelo manejo inadequado dos recursos ambientais $58 \%$ dos entrevistados consideram as queimadas e o lixo, $25 \%$ as queimadas, e $17 \%$ o lixo e os agrotóxicos. Perceber que os agricultores tem uma carência de informações sobre as questões básicas de convivência harmoniosa com o meio ambiente cometendo manejo inadequado nos agroecossistemas familiar que pode comprometer a sua estrutura física, química e biológica.
\end{abstract}

Palavras-chave: Agricultura familiar, Diagnostico, Reflexão

\begin{abstract}
The agricultural environment is the subject of speculation and study with the aim of improving the design of agroecosystems without interfering aggressively to achieve the welfare of the community and preserving the environment is only possible through sustainable management of agricultural systems. The work aimed to identify the socio-economic profile of the farmers and their care with environmental issues in production units Moura community. To perform the work visits were made to the community during the month of August 2013, and the survey interviews with the aid of semi-structured questionnaires consisting of questions of social, environmental and agricultural character were performed. Farmers in the Moura community, $44 \%$ were male and $54 \%$ female, $67 \%$ have $1-2$ minimum wages and $33 \%$ less than a minimum wage, the existing environmental problems in the community caused by improper management of environmental resources $58 \%$ of respondents consider fires and trash fires $25 \%$, and $17 \%$ trash and pesticides. Realizing that farmers have a lack of information on basic issues of harmonious coexistence with the environment making improper management in agroecosystems family that can compromise their physical, chemical and biological structure.
\end{abstract}

Environmental

Keywords: Family farming, Diagnosis, reflection 


\section{INTRODUÇÃO}

Nos últimos anos o ambiente agrícola é alvo de especulação e estudo com intuito de aperfeiçoar o desenho dos agroecossistemas sem interferir de forma agressiva contribuindo assim com as gerações futuras. Os agroecossistemas familiares são caracterizados pela diversidade de cultivos de espécies para a subsistência da família e comercialização do excedente, tornando as unidades produtivas ecologicamente sustentáveis.

Segundo Barreto (2010) a diversificação busca o atendimento das necessidades das famílias, principalmente para sua alimentação, e para uma série de consumos intermediários, sobretudo na alimentação do gado e de pequenos animais, além da contribuição das diversas atividades na composição da renda monetária da propriedade.

Atualmente a agricultura familiar, mesmo com menores áreas disponíveis, ocupa $84 \%$ dos estabelecimentos e, ainda, é o segmento responsável pela maior oferta de alimentos básicos para a população, representando $87, \%$ da mandioca produzida, $70 \%$ do feijão, $46 \%$ do milho, $58 \%$ do leite, $50 \%$ das aves e $59 \%$ dos suínos (BRASIL, 2009). A prática agrícola por si só causa danos no ambiente, no entanto temos que tentar minimizar esses danos através de manejo alternativos que visem à preservação dos recursos naturais.

Para Costabeber (2004) a redução dos impactos ecológicos da atividade agrícola é possível com uma maior racionalização do processo produtivo, via redução de insumos industriais, incorporando tecnologias consideradas ambientalmente mais corretas, reduzindo os custos de produção, mantendo os níveis de produtividade.

Segundo o IBGE (2006) na agricultura familiar existe mais preservação, mais cobertura florestal e mais respeito ao meio ambiente, os agricultores conseguem produzir com mais eficiência, sem necessariamente destruir o entorno. Acredita-se que para atingir o bem-estar social da comunidade e a preservação do meio ambiente só é possível mediante manejos sustentáveis dos sistemas agrícolas familiares.

Diante da necessidade de melhorar as condições de harmonia dos agricultores com o meio em que vivem e trabalham objetivou-se identificar o perfil socioeconômico dos agricultores e os seus respectivos cuidados com as questões ambientais nas unidades produtivas da comunidade Moura.

\section{METODOLOGIA}

Para a realização do trabalho foram feitas visitas comunidade no mês de Agosto de 2013, para realizar o levantamento foram utilizados entrevistas com auxilio de questionários semiestruturados com 12 famílias da comunidade Moura. A mesma fica localizada há aproximadamente 12 $\mathrm{km}$ do município de Bananeiras, constituindo-se de treze famílias que residem nessa dependência.

De acordo com o Instituto Brasileiro de Geografia e Estatística (IBGE), no ano de 2013 a população de Bananeiras estimada é 22.012 habitantes distribuídos em uma área territorial de $258 \mathrm{~km}^{2}$. Localizada na Serra da Borborema, região do Brejo paraibano, a $141 \mathrm{~km}$ de João Pessoa, $150 \mathrm{~km}$ de Natal e a $70 \mathrm{~km}$ de Campina Grande, com altitude de 526 metros, possui clima mais ameno que a média do agreste paraibano.

O questionário foi constituído de questões de caráter Social: gênero, escolaridade e estrutura econômica. Ambiental: Quais as consequências que você enxergar na sua comunidade causada pelo manejo inadequado na natureza; Qual o destino que você dar ao lixo. Agrícola: Utiliza algum tipo de técnica nas fruteiras; Quais as culturas plantadas; Qual o destino de sua produção.

\section{RESULTADOS E DISCUSSÕES}

Para obter as informações referentes ao gênero, escolaridade e renda familiar, adotouse a metodologia baseado em Luna (2005), que considera essas informações obtidas em factuais e as opinativas as que expressa a opinião com relação às questões indagadas. Após a coleta dos dados os mesmos foram devidamente tabulados, interpretados e apresentados através de gráficos, como apresentados a seguir. Conforme a entrevista realizada com os agricultores da comunidade Moura, $44 \%$ são do gênero masculino e $54 \%$ feminino. Foram entrevistado 12 famílias, das 13 famílias residentes na comunidade.

Dentre os moradores $8 \%$ possuem ensino médio, $17 \%$ têm o ensino fundamental completo, $25 \%$ têm o ensino fundamental incompleto e $50 \%$ dos entrevistados são analfabetos observa-se que dos entrevistados a metade dos agricultores da comunidade Moura nunca frequentaram a escola (Figura 1). Em um estudo realizado no bairro Piteira em Conceição do Macabu/RJ, por Domingos (2008) informa que 3,2\% dos entrevistados afirmaram possuir ensino superior e 19,4\% ensino médio. A maior percentagem, 32,3\% referese às pessoas que possuem ensino fundamental incompleto até a $4^{\circ}$ série; $19,4 \%$ possuem o ensino 
fundamental incompleto entre $5^{\circ}$ e $8^{\circ}$ série; $22,6 \%$ afirmaram que nunca estudaram. Analisando-se os resultados verifica-se que os mesmos guardam uma relativa proximidade com os valores encontrados na comunidade Moura.

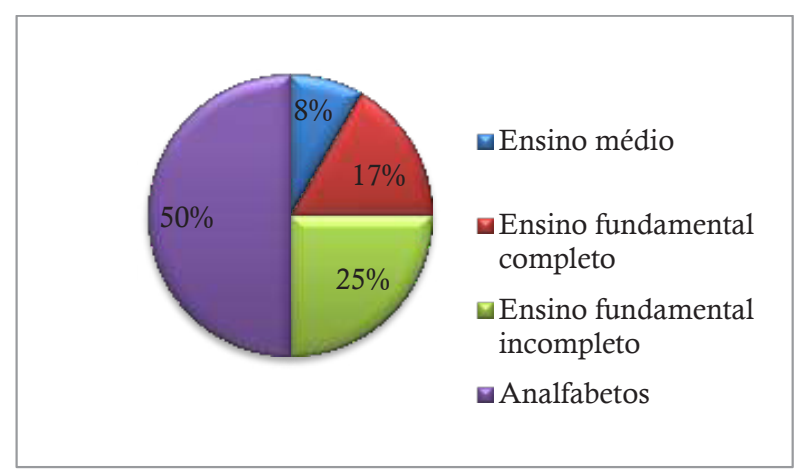

Figura 1: Grau de escolaridade dos agricultores entrevistados na comunidade Moura, 2013.

Quando questionado em relação à renda familiar $67 \%$ tem de 1 a 2 salários mínimos e $33 \%$ menos de um salário mínimo, muitos completam a subsistência da família com a venda de produtos oriundos da agricultura familiar produzido na própria comunidade de acordo com o que esta sendo produzido no momento.

Ao perguntar na concepção de cada agricultor, quais os problemas ambientais existentes na comunidade causado pelo manejo inadequado dos recursos ambientais, $58 \%$ dos entrevistados consideram as queimadas e o lixo, $25 \%$ as queimadas, e $17 \%$ o lixo e os agrotóxicos utilizados por agricultores para o controle de insetos nas fruteiras (Figura 2). Eberhardt (2007) ao perguntar para os moradores de um bairro quais os principais problemas ambientais existentes $45,8 \%$ responderam ser o lixo o principal problema existente e $13,8 \%$ as queimadas.

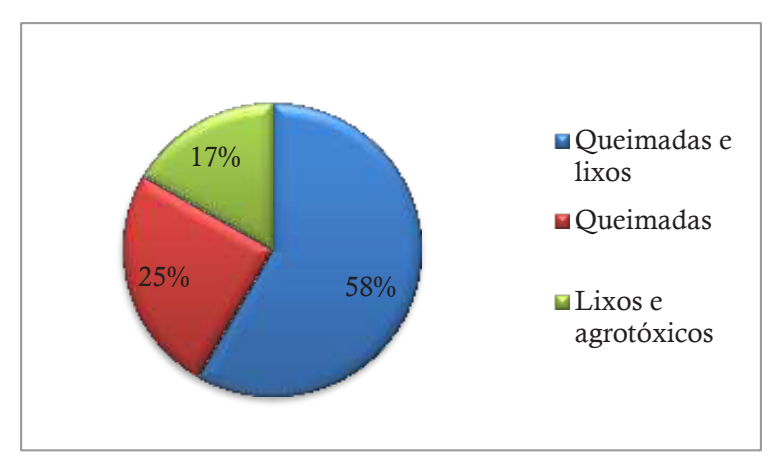

Figura 2. Quais as consequências que você enxergar na sua comunidade causada pelo manejo inadequado dos recursos ambientais?
A questão do lixo está diretamente ligada ao modelo de desenvolvimento em que vivemos, vinculada ao incentivo do consumo, pois muitas vezes adquirimos coisas que não são necessárias.

A partir de pequenas ações que podem partir de dentro de casa, tais como, separar o lixo orgânico de lixo reciclável, evitar jogar lixo em vias públicas, estradas e rios. Essas são apenas algumas ações que podem ser praticadas para diminui os impactos do lixo ao meio ambiente.

É evidente o hábito que os agricultores da comunidade têm de praticar a queima dos restos culturais, prática está para alguns inofensivos, entretanto é responsável por uma série de danos a saúde humana e ambiental mais que poucas pessoas do campo têm essas preocupações, muitas das vezes, por não terem conhecimento dos seus benefícios químicos, físicos e biológicos ao solo quando deixados para decompor sobre o solo.

A produção de lixo pelas pessoas é algo inevitável, no entanto quando perguntado qual o destino final dado ao lixo produzido no dia-a-dia dos entrevistados 50\% costumam queimar, 33\% joga a céu aberto e 17\% enterra (Figura 3).

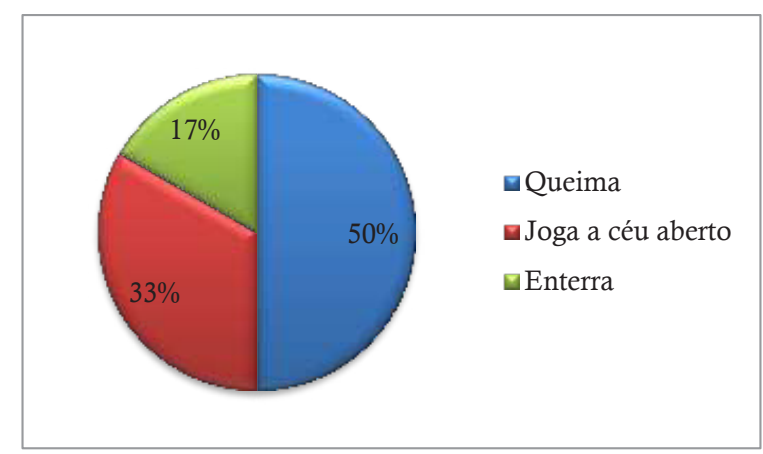

Figura 3. Qual o destino dado ao lixo produzido no dia-a-dia?

A deposição a céu aberto do lixo causa grande prejuízo ao meio ambiente, e esses continua sendo o destino da maior parte dos resíduos produzidos pela população. A disposição final e adequada do lixo pode influir na qualidade do meio ambiente e na saúde do homem, além da preservação dos recursos naturais (SOARES; SALGUEIRO; GAZINEU, 2007). E ao descartar de forma inadequada os resíduos vários problemas são gerados como, por exemplo, poluição da água através do chorume produzido pela decomposição da matéria orgânica presente no lixo, proliferação de vetores de doenças (ratos, moscas, baratas, mosquitos entre outros).

Os agricultores da comunidade Moura têm no complemento da renda familiar as frutas provenientes da agricultura de subsistência destacando mangas, laranja, castanha de caju, banana, abacate, 
laranja, goiaba e maracujá, sendo que $67 \%$ da produção são destinadas para o consumo alimentar da família, 22\% é comercializado nas feiras livres das regiões vizinhas e $8 \%$ não produz nada em sua propriedade (Figura 4). Segundo dados do IBGE (2012) na cidade de Bananeiras foram produzidos $1.879^{-1}$ das frutas citadas pelos agricultores, sendo distribuídas por manga $70^{-1}$, laranja $12^{-1}$, castanha de caju $80^{-1}$, banana $1700^{-1}$, abacate $10^{-1}$, goiaba $2^{-1}$ e maracujá $5^{-1}$. Esses dados mostra a importância da agricultura familiar, devido a diversidades de cultura, o agricultor sempre dispõe de uma renda extra para complementar o sustento da família.

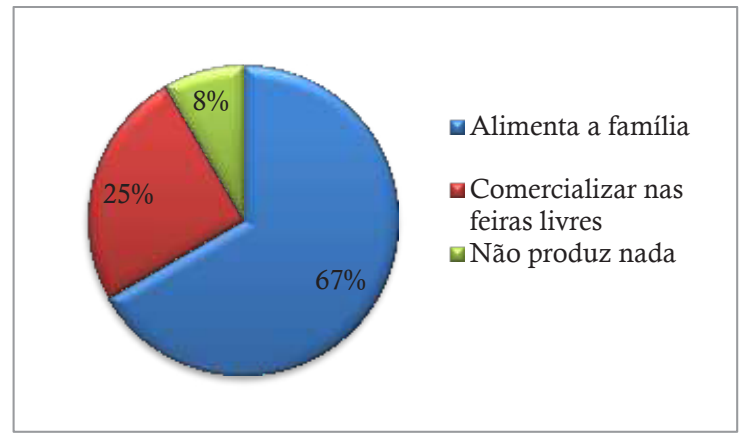

Figura 4: Qual o destino dado à produção agrícola familiar?

Ao perguntar sobre as técnicas utilizadas nas fruteiras, 58\% dos agricultores responderam utilizarem adubos orgânicos, ou seja, estercos dos animais da propriedade, $25 \%$ utiliza cobertura morta com os restos culturais e $17 \%$ não costumam utilizam nada nas fruteiras (Figura 5).

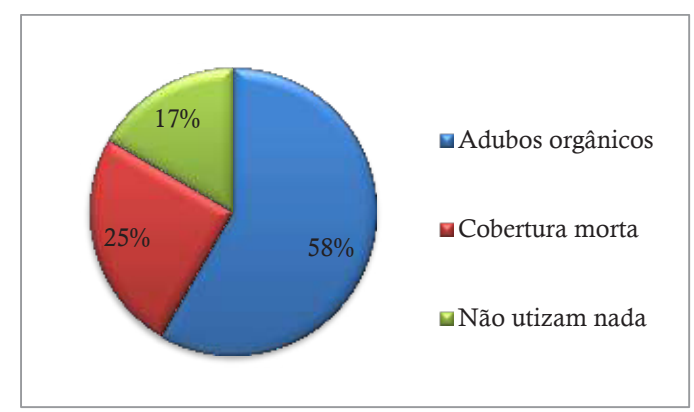

Figura 5: Quais as técnicas utilizadas nas fruteiras?

A finalidade para o uso de esterco é para nutrir as plantas e adubar o solo segundo os agricultores entrevistados. Além disso, o esterco produzido na propriedade contribui para a garantia da sustentabilidade orgânica e econômica do sistema agrícola, reduzindo e eliminando a necessidade de comprar adubos químicos ou mesmo esterco de outras propriedades, que além de aumentar os gastos de produção pode ser uma forte de contaminação por doenças e pragas ou até mesmo vestígios de agrotóxicos (TOSETTO; CARDOSO; FURTADO, 2013).

Além de economizarem nos insumos e não utilizarem produtos químicos, os agricultores produzem frutas sem resíduos de agrotóxicos melhorando sua condição de vida e contribuindo como individuo na preservação do meio ambiente.

\section{CONSIDERAÇÕES FINAIS}

Percebemos que os agricultores tem uma carência de informações sobre as questões básicas de convivência harmoniosa com o meio ambiente, cometendo manejo inadequado nos agroecossistemas familiares o que pode comprometendo as estrutura física, química e biológica do solo implicando assim na sustentabilidade da unidade produtiva interferindo no bem estar das gerações futuras inclusive os seus filhos e netos.

No entanto são pessoas acessíveis e estão abertos ao dialogo demonstrando interesse na reestruturação de valores sociais e ambientais que possam a vir melhorar a sua qualidade de vida. Cabe aos profissionais intervir nesta comunidade munidos de informações para melhorar o meio em que eles vivem de modo a respeita os seus conhecimentos e respeitando suas culturas.

\section{REFERÊNCIAS}

BARRETO, H. F. M. Impacto do manejo agroecológico da caatinga em unidades de produção familiar no Oeste Potiguar. 2007. 143f. (Dissertação Mestrado em Ciência Animal) Universidade Federal Rural do Semiárido, Mossoró, 2010.

BRASIL. Ministério do Desenvolvimento Agrário. Agricultura familiar no Brasil e o censo

Agropecuário, Brasília, p. 92009.

COSTABEBER, J. A. Transição agroecológica: do produtivismo à ecologização. In: CAPORAL, F. R.; COSTABEBER, J. A. Agroecologia e extensão rural: contribuições para a promoção de desenvolvimento rural sustentável. Brasília: MDA/SAF/DATER -IICA, cap. 2, p.17-48, 2004.

EBERHARDT, D. A.; ARAÚJO R. K.; SILVA, N. T.S.; BURIOL, G. A.; Diagnóstico socioambiental da comunidade da bacia escola hidrográfica urbana, Santa Maria - RS. Disc. Scientia. Série: Ciências Naturais e Tecnológicas, S. Maria, v. 8, n. 1, p. 
55-68, 2007.

INSTITUTO BRASILEIRO DE GEOGRAFIA E ESTATÍSTICA (IBGE) 2006. Disponível em: < http:// www.ibge.org.br $>$ Acesso em 20 jan. 2014.

INSTITUTO BRASILEIRO DE GEOGRAFIA E ESTATÍSTICA (IBGE). Infográficos: dados gerais do município. 2013. Disponível em: < http://cidades.ibge.gov.br/xtras/home.php > Acesso em 18 jan. 2014.

LUNA, S. V. Planejamento de pesquisa: uma introdução. São Paulo: EDUC, 2005. 108 p. (Série Trilhas).

SOARES, L. G. C.; SALGUEIRO, A. A.;

GAZINEU, M. H. P.; Educação ambiental aplicada aos resíduos sólidos na cidade de Olinda, Pernambuco - um estudo de caso. Revista Ciências e Tecnologia, n. 1, p. 1-9, 2007.

TOSETTO, E. M.; CARDOSO, I.M.; FURTADO, S.D. C.; A importância dos animais nas propriedades familiares rurais agroecológicas. Revista Brasileira de Agroecologia, v.8(3), p.12-25, 2013. 